\title{
Role of Artificial Sweeteners in Development of Type 2 Diabetes Mellitus (DM): A Review
}

\author{
Article by Jagan Nadipelly ${ }^{1}$, Niharika Anand ${ }^{2}$ and Hannah Persaud ${ }^{3}$ \\ ${ }^{1}$ Faculty of Medicine- Pharmacology, Texila American University, Guyana, South America \\ ${ }^{2}$ Doctor of Medicine (MD1), Texila American University, Guyana, South America \\ ${ }^{3}$ Faculty of Premedical-Biology and Clinical Nutritionist, Texila American University, Guyana, \\ South America \\ E-mail: jaganalwaysright@gmail.com ${ }^{1}$,niha1798@gmail.com ${ }^{2}$,hannah.persaud@tau.edu.gy
}

\begin{abstract}
A number of lifestyle factors are known to be important to the development of type 2 Diabetes mellitus (DM). These are physical inactivity, sedentary lifestyle, cigarette smoking, dietary habits and generous consumption of alcohol. Recently, it has been reported that 385 million people had diabetes and the number of people with type 2 DM is increasing in every year. Obesity has been found to contribute to approximately 55\% of cases of type 2 DM. Consumption of sugar-sweetened beverages has been increasingly associated with obesity and type 2 DM. Hence, many people have turned to high-intensity sugar substitute sweeteners like aspartame, sucralose and saccharin as a way to reduce the risk of these consequences. However, accumulating evidence suggests that frequent consumers of these sugar substitutes may also be at increased risk of excessive weight gain, metabolic syndrome, type 2 diabetes and cardiovascular disease. A rise in the percent of the population who are obese coincides with an increase in the widespread use of noncaloric artificial sweeteners, such as aspartame (e.g., Diet Coke) and sucralose (e.g., Pepsi), in food products. This paper discusses these findings and considers the hypothesis that consuming sweet-tasting but noncaloric or reduced-calorie food and beverages interferes with learned responses that normally contribute to glucose and energy homeostasis. Because of this interference, frequent consumption of high-intensity sweeteners may have the counterintuitive effect of inducing metabolic derangements. This review is based on a search of articles published in PUBMED, Medline, the Cochrane Database of Systemic Reviews, and mainly focused on type 2 diabetes mellitus, current diagnosis, treatment and role artificial sweeteners in development of diabetes.
\end{abstract}

Keywords: Type 2 diabetes mellitus; Artificial Sweeteners; Obesity

\section{Type 2 diabetes mellitus (T2DM)}

Type 2 diabetes mellitus is a metabolic disorder characterized by glucose intolerance and insulin resistance leading to hyperglycemia. Type 2 diabetes mellitus (T2DM) is a global epidemic with an estimated worldwide prevalence of $6 \%$ (246 million people) in 2007, and forecast to rise to $7.3 \%$ (380 million) by 2025 . The health, social, and economic burden is great [1,2]; consequently, T2DM presents a major challenge to healthcare systems around the world. T2DM is a complex disorder in which the interaction between environmental and genetic factors results in the development of insulin resistance and $\beta$-cell dysfunction [3, 4]. The development of insulin resistance precedes the onset of T2DM by many years [5] and is influenced by many factors including puberty, ageing, pregnancy, physical activity and oral intake [5 - 9]. Obesity is the single most important contributor to insulin resistance [9] modulating insulin sensitivity via multiple factors including imbalance of hormones (leptin and adiponectin), cytokines (tumour necrosis factor- $\alpha$, interleukin-6), suppressors of cytokine signalling (SOCS), inflammatory signalling pathways (nuclear factor-KB and IKB Kinase) and retinol binding protein-4 [10 - 13]. The most crucial factor relating obesity to insulin resistance is thought to be the release of nonesterified fatty acids (NEFAs) particularly from intra-abdominal fat. Increased NEFAs result in increased 
intracellular diacylglycerol and fatty acyl-co A., which result in phosphorylation of insulin-receptor substrate -1 (IRS-1) and insulin-receptor substrate (IRS-2); this in turn diminishes downstream events of the insulin receptor signalling resulting in insulin resistance [14]. Despite obesity being the single most important contributor to IR; most obese insulin-resistant individuals do not develop T2DM [15] because their $\beta$-cells are capable of producing significantly elevated levels of insulin to maintain glycaemic control [16 - 18]. Hence, the failure of $\beta$-cells to secrete sufficient insulin to overcome insulin resistance (i.e., $\beta$-cell dysfunction) is the crucial step in the development and progression of T2DM $[19,20]$. The reason for the decline in $\beta$-cell function is not entirely clear, but appears to involve hyperglycaemia per se, together with excessive production of NEFAs, amyloid formation and genetic factors [21 - 24]. In addition to $\beta$-cell dysfunction, patients with T2DM have pancreatic $\alpha$-cell dysfunction manifesting as elevated (or non-suppression of) glucagon secretion in the presence of hyperglycemia [25].

Obesity has been strongly linked with type 2 DM, and nearly $90 \%$ of individuals with diabetes have overweight or obesity [26]. Sugar consumption is one of the common suspected culprits for the rise in obesity and may contribute to the development of type 2 DM [27]. Consequently, artificial sweeteners are commonly consumed by individuals with obesity and type 2 diabetes as they are thought to lower the caloric content and blood glucose response. However, recent studies have proven that, use of artificial sweeteners may also increase weight gain over time [28], and may promote glucose intolerance through the altered function and composition of intestinal microbiota [29].

\section{Complications of diabetes}

Chronic hyperglycemia causes many of the major complications of diabetes, including nephropathy, retinopathy, neuropathy, macro and microvascular damage. The risk for microvascular and neuropathic complications is related to both duration of diabetes and the severity of hyperglycemia [30]. In particular, diabetes increases the risk of microvessel disease [31, 32]. As a result, serious conditions such as retinopathy, neuropathy and nephropathy are frequently encountered among patients with diabetes. Diabetic retinopathy is estimated to account for 5\% of all cases of blindness globally [33] and up to 50\% of patients receiving renal replacement therapy have diabetic nephropathy [34]. Diabetic peripheral neuropathy (DPN) is associated with considerable morbidity, mortality and diminished quality of life and affects up to 50\% of people with diabetes [35]. Hyperglycemia is a pre-requisite for the development of diabetic complications and in chronic diabetes, hyperglycemia instigates activations of hexosamine biosynthetic pathway, sorbitol- aldose reductase pathway [36], mitogen activated protein kinases (MAPKs) [37] and protein kinase C [38]. Further, hyperglycemia increases the expression of growth factors and cytokines such as transforming growth factor- $\beta$ (TGF- $\beta$ ), vascular endothelial growth factor (VEGF), platelet-derived growth factor, insulin-like growth factor (IGF) and tumor necrosis factor- $\alpha$ $(\mathrm{TNF}-\alpha)$. Reactive oxygen species (ROS) are important arbitrator factors involved in all these events [39, 40] and activate intracellular signal transduction and transcription cascades, in which MAPKs and nuclear factor kappa B (NF-kB) play the most significant roles $[41,42]$ and damage proteins, lipids, and nucleic acids by oxidation (Fig. 1). Clinical studies have demonstrated that chronic diabetic complications occur late after disease onset, reflecting structural abnormalities in nerves, kidney, retina and blood vessels, with the appearance strongly correlated with the duration of the diabetes and the level of glycemic control [43]. Large clinical trials have demonstrated that normalization of glycemia can greatly reduce the incidence of diabetic complications. However, in clinical practice, normalizing blood glucose is not a trivial task and almost 50\% of diabetic subjects fail to reach the recommended target of an HbA1c lower than 7\% [44]. Based on the present perceptive of pathophysiology of diabetes mellitus, plentiful pharmacological and non pharmacological interventions have been employed in the previous 50 years in order to treat hyperglycemia and interrupt the progression of disease. However, most of the observed initial improvements in hyperglycemia are not constant because of the progressive nature of disease [45]. These pharmacotherapies also have undesired side effects, such as hypoglycemia, weight gain, gastrointestinal symptoms and peripheral edema, variable effects on $\beta$-cell function and decline [46, 47]. 


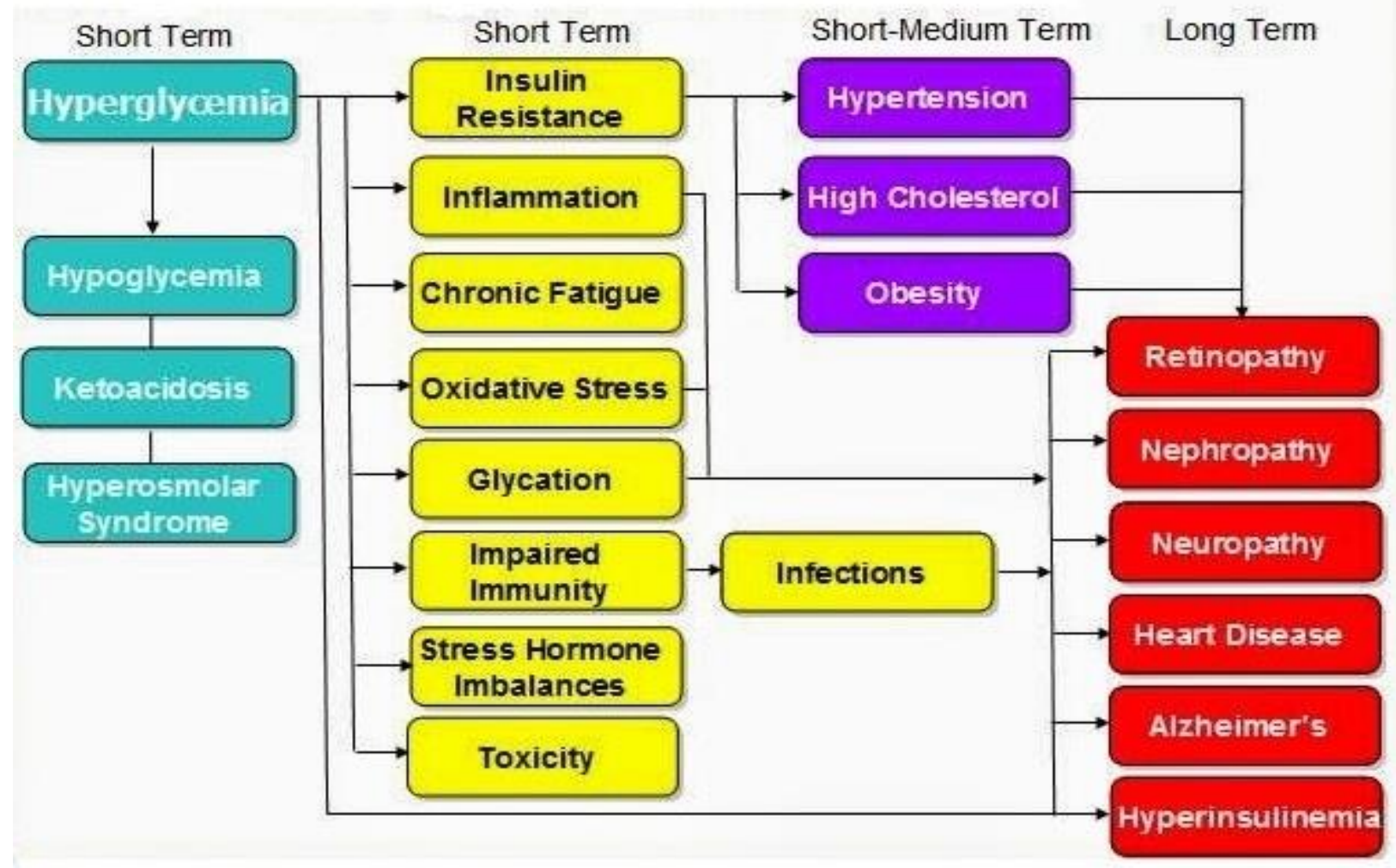

Figure 1. Complications of type 2 diabetes mellitus

\section{Current treatment options for diabetes}

Based on the current understanding of the pathophysiology of T2DM, multiple pharmacological and non-pharmacological interventions have been developed over the past five decades with the aim of improving glycaemic control and hopefully slowing disease progression. Treatment modalities include lifestyle modifications, treatment of obesity, oral hypoglycemic agents, and insulin sensitizers like metformin, a biguanide that reduces insulin resistance, is still the recommended first line medication especially for obese patients. Other effective medications include non-sulfonylurea secretagogues, thiazolidinediones, alpha glucosidase inhibitors, and insulin. Recent research into the pathophysiology of type $2 \mathrm{DM}$ has led to the introduction of new medications like glucagon like peptide 1 analogoues: dipeptidyl peptidase-IV inhibitors, inhibitors of the sodium-glucose cotransporter 2 and 11shydroxysteroid dehydrogenase 1, insulin-releasing glucokinase activators and pancreatic-G-proteincoupled fatty-acid-receptor agonists, glucagon-receptor antagonists, metabolic inhibitors of hepatic glucose output and quick-release bromocriptine. Inhaled insulin was licensed for use in 2006 but has been withdrawn from the market because of low patronage. These treatments may also have undesired side effects, such as hypoglycemia, weight gain, gastrointestinal symptoms and peripheral oedema, in addition to variable effects on $\beta$ - cell function and decline [46, 47]. Hence, interventions that can slow and/or reverse $\beta$-cell decline, which result in weight loss (or at least cause no weight gain) and have low risk of hypoglycemia, might be expected to have an important impact in patients with T2DM. Incretin-based therapies are a new class of antidiabetic medication that may address some of the abovementioned shortfalls of current treatments. In addition, other therapies are in development with the potential to address some of the disadvantages of currently available treatments. 
DOI: $10.21522 /$ TIJBMS.2016.02.02.Art008

ISSN: $2519-500 \mathrm{X}$

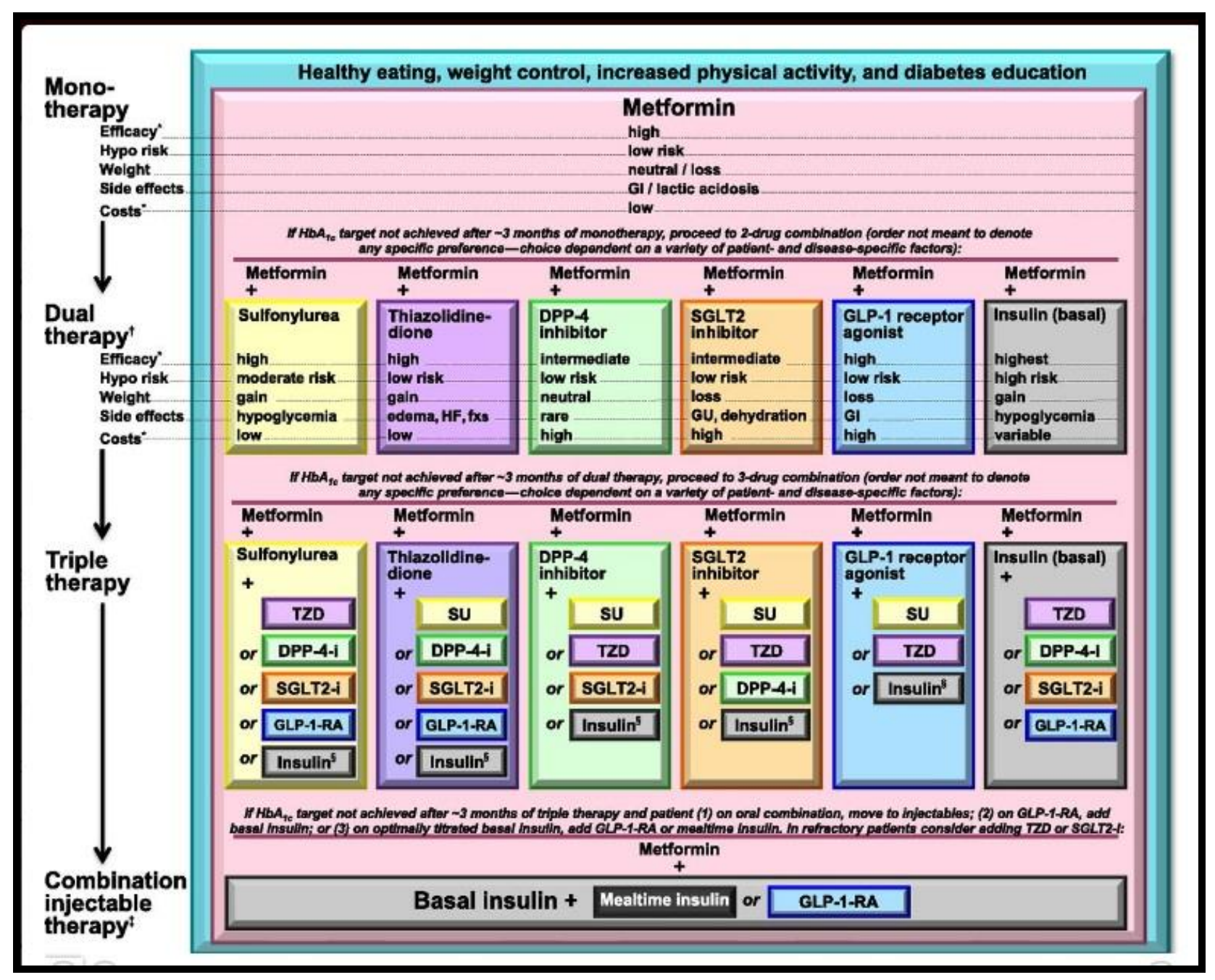

Figure 2. Strategies for treatment of type 2 diabetes miletus (DM).

Source: Silvio inzucchi et al., 2015, diabetes care 38(1): 140-149.

\section{Role of artificial sweeteners in development of type $2 \mathrm{DM}$}

There are five artificial sweeteners currently ruling the arena of food processing, which include saccharin, neotame, acesulfame potassium, aspartame, and sucralose. Of the five main artificial sweeteners, sucralose and aspartame are the most pervasive and dangerous substitutes found in products on store shelves today. All these artificial sweeteners are marketed under the names of Splenda, Equal and NutraSweet and there are many everyday eatable products such as yogurt, sodas, pudding, tablets, chewing gum, bread, etc consist of these artificial sweeteners.

Many accumulating evidence suggests that frequent consumption of these sugar substitutes may increase risk of excessive weight gain, metabolic syndrome, type 2 diabetes, and cardiovascular disease. $[48,49]$. Significant risk of weight gain, obesity, increased body mass index (BMI) and increased body fat percentage in males and females after consumption of artificial sweeteners containing food products was observed in few recent studies [50, 51]. Several large-scale studies, including the National Health and Nutrition Examination Survey (NHANES) and the San Antonio Heart study, have shown a associations between artificial sweetener intake and incidence of the metabolic syndrome and its components, including waist circumference, blood pressure, and fasting blood glucose [52, 53]. Recent studies conducted in adults have demonstrated the link between artificial sweetener consumption and insulin 
resistance, incidence of type 2 diabetes, and poor glucose control in patients with pre-existing diabetes [54]. In the European E3N study and the Health Professionals Follow-up (HPFS) [55] risk for type two diabetes was more than doubled for participants in the highest quartile of artificial sweeteners consumption compared with non-consumers. Most recently, data from the European Prospective Investigation into Cancer and Nutrition (EPIC) has also indicated that risk for type two diabetes was elevated in those consuming at least one artificial sweetener per day [56]. A study conducted by Pepino et al. (2013) [57] and Suez et al., (2014) [58] demonstrates a deleterious effect increasing glucose concentrations in subjects with a high degree of obesity after an acute and a 7-day exposure to sucralose and saccharin, respectively.

\section{Mechanism of artificial sweeteners in development of diabetes}

Several mechanisms have been proposed to account for the association between artificial sweetener use and diabetes. Recent research have provided convincing evidence that artificial sweeteners play an active role in the gastrointestinal tract, thus providing a mechanistic explanation for observed metabolic effects. Sweet-taste receptors, including the taste receptor T1R family and $\alpha$-gustducin, respond to artificial sweeteners [59, 60]. In both humans and animals, these receptors have been situated in gastrointestinal tract and glucagon-like peptide-1 (GLP-1) [61]. Consumption of artificial sweeteners containg products along with normal day to day food products resulting in stimulation of taste receptors in GI tract and secretion of more amount of GLP-1 [62]. This could lead to more and rapid absorption food materials from intestine into the blood stream and as well as increase GLP-1 stimulates insulin, which enhances the glucose absorption by cells and eventually it lead to weight gain and central visceral adiposity. Many previous studies revealed the crucial role of adiposity in the pathogenesis of type 2 diabetes.

\section{References}

[1]. Burcelin, R., Knauf, C., \& Cani, P. D. Pancreatic alpha-cell dysfunction in diabetes. Diabetes Metab 2008; 34 (Suppl 2): 49-55.

[2]. Barroso, I. Genetics of type 2 diabetes. Diabet Med 2005; 22: 517-535.

[3]. Brownlee, M. Biochemistry and molecular cell biology of diabetic complications. Nature 2001; 414, 813-820.

[4]. Black, C., Donnelly, P., McIntyre, L., Royle, P.L., Shepherd, J.P., Thomas, S. Meglitinide analogues for type 2 diabetes mellitus. Cochrane Database of Systematic Reviews 2007.

[5]. Brown RJ, Walter M, Rother KI. Ingestion of diet soda before a glucose load augments glucagon like peptide1. Diab care 2009; 32(12):2184-2186.

[6]. Brown RJ, et al. Artificial sweeteners: a systematic review of metabolic effects in youth. Int J Pediatr Obes. 2010; 5:305-312.

[7]. Buchanan, T. A., Metzger, B. E., Freinkel, N., \& Bergman, R. N. Insulin sensitivity and B-cell responsiveness to glucose during late pregnancy in lean and moderately obese women with normal glucose tolerance or mild gestational diabetes. Am J Obstet Gynecol 1990; 162: 1008-1014.

[8]. Chen, M., Bergman, R. N., \& Porte, D. Insulin resistance and [beta]-cell dysfunction in aging: the importance of dietary carbohydrate. J Clin Endocrinol Metab 1988; 67: 951-957.

[9]. Dhingra R, Sullivan L, Jacques PF, et al. Soft drink consumption and risk of developing cardio metabolic risk factors and the metabolic syndrome in middle-aged adults in the community. Circulation 2007; 116(5):480-488.

[10]. Del, P.S., Bianchi, C., Marchetti, P. Beta-cell function and anti-diabetic pharmacotherapy. Diabetes/Metabolism Research and Reviews 2007; 23: 518-527.

[11]. De Koning L, et al. Sugar-sweetened and artificially sweetened beverage consumption and risk of type 2 diabetes in men. Am J Clin Nutr. 2011; 93:1321-1327.

[12]. Dunlop, M. Aldose reductase and the role of the polyol pathway in diabetic nephropathy. Kidney International 2000; 77: 3-12.

[13]. DeFronzo, R. A. (1979). Glucose intolerance of aging. Evidence for tissue insensitivity to insulin. Diabetes 1979; 28: 1095-1101. 
DOI: $10.21522 /$ TIJBMS.2016.02.02.Art008

ISSN: $2519-500 \mathrm{X}$

[14]. De Groot, M., Anderson, R., Freedland, K. E., Clouse, R. E., \& Lustman, P. J. Association of depression and diabetes complications: a meta-analysis. Psychosom Med 2001; 63: 619-630.

[15]. Fowler SP, et al. Fueling the obesity epidemic? Artificially sweetened beverage use and long-term weight gain. Obesity (Silver Spring). 2008; 16:1894-1900.

[16]. Fagherazzi G, et al. Consumption of artificially and sugar-sweetened beverages and incident type 2 diabetes in the Etude Epidemiologique aupres des femmes de la Mutuelle Generale de l'Education Nationale-European Prospective Investigation into Cancer and Nutrition cohort. Am J Clin Nutr. 2013; 97:517-523

[17]. Facchini, F. S., Hua, N., Abbasi, F., \& Reaven, G. M. Insulin resistance as a predictor of age-related diseases. J Clin Endocrinol Metab 2001; 86: 3574-3578.

[18]. Goodyear, L. J., \& Kahn, B. B. Exercise, glucose transport, and insulin sensitivity. Annu Rev Med 1998; 49: 235-261.

[19]. Hu, F.B., and Malik, V.S. Sugar-sweetened beverages and risk of obesity and type 2 diabetes: epidemiologic evidence. Physiol. Behav 2010; 100: 47-54.

[20]. Hoogwerf, B.J., Complications of diabetes mellitus. International Journal of Diabetes in Developing Countries 2005; 25: 63-69.

[21]. Hoerger, T.J., Segel, J.E., Gregg, E.W., Saaddine, J.B. Is glycemic control improving in U.S. adults? Diabetes Care 2008; 31, 81-86.

[22]. Hull, R. L., Westermark, G. T., Westermark, P., \& Kahn, S. E. (2004). Islet amyloid: a critical entity in the pathogenesis of type 2 diabetes. J Clin Endocrinol Metab 2004; 89: 3629-3643.

[23]. Jacobson, A. M. Impact of improved glycemic control on quality of life in patients with diabetes. Endocr Pract 2004; 10: 502-508.

[24]. Jang HJ, Kokrashvili Z, Theodorakis MJ, et al. Gut-expressed gustducin and taste receptors regulate secretion of glucagonlike peptide-1. Proc Natl Acad Sci USA 2007; 104(38):15069-15074.

[25]. Kahn, S. E. (1993). Quantification of the relationship between insulin sensitivity and Bcell function in human subjects. Evidence for a hyperbolic function. Diabetes 1993; 42: 1663-1672.

[26]. Koshikawa, M., Mukoyama, M., Mori, K., Suganami, T., Sawai, K., Yoshioka, T., Nagae, T., Yokoi, H., Kawachi, H., Shimizu, F., Sugawara, A., Nakao, K. Role of p38 mitogen-activated protein kinase activation in podocyte injury and proteinuria in experimental nephrotic syndrome. Journal of American Society of Nephrology 2005; 16: 2690-2701.

[27]. Kutner, N.G., Johansen, K.L., Zhang, R., Huang, Y., Amaral, S. Perspectives on the new kidney disease education benefit: early awareness, race and kidney transplant access in a USRDS study. American Journal of Transplantion 2012; 12, 1017-1023.

[28]. Kahn, S. E., Haffner, S. M., Heise, M. A., Herman, W. H., Holman, R. R., Jones, N. P., et al. Glycemic durability of rosiglitazone, metformin, or glyburide monotherapy. N Engl J Med 2006; 355: 2427-2443.

[29]. Laska MN, et al. Longitudinal associations between key dietary behaviors and weight gain over time: transitions through the adolescent years. Obesity (Silver Spring). 2012; 20:118-125.

[30]. Lutsey PL, Steffen LM, Stevens J. Dietary intake and the development of the metabolic syndrome: the Atherosclerosis Risk in Communities study. Circulation 2008; 117(6):754-61.

[31]. Lee, M.-J., Feliers, D., Mariappan, M.M., Sataranatarajan, K., Sataranatarajan, K., Mahimainathan, L., Musi, N., Foretz, M., Viollet, B., Weinberg, J.M., Choudhury, G.G., Kasinath, B.S. A role for AMP activated protein kinase in diabetes-induced renal hypertrophy. American Journal of Physiology - Renal Physiology 2007; 292: 617627.

[32]. Meier, M., Menne, J., Park, J.K., Haller, H. Nailing down PKC isoform specificity in diabetic nephropathy two's company, three's a crowd. Nephrology Dialysis Transplant 2007; 22: 2421-2425.

[33]. Mackenzie T, Brooks B, O'Connor G. Beverage intake, diabetes, and glucose control of adults in America. Ann Epidemiol 2006; 16(9):688-691.

[34]. McNaughton SA, Mishra GD, Brunner EJ. Dietary patterns, insulin resistance, and incidence of type 2 diabetes in the Whitehall II study. Diabetes Care 2008; 31(7):1343-1348. 
[35]. Mooney, R. A. Suppressors of cytokine signaling-1 and -6 associate with and inhibit the insulin receptor. A potential mechanism for cytokine-mediated insulin resistance. J Biol Chem 2001; 276: 25889-25893.

[36]. Mace OJ, Affleck J, Patel N, et al. Sweet taste receptors in rat small intestine stimulate glucose absorption through apical GLUT2. J Physiol 2007; 582(Pt 1):379-392.

[37]. Nelson G, Hoon MA, Chandrashekar J, et al. Mammalian sweet taste receptors. Cell 2001; 106(3): 381-390.

[38]. Perley, M., \& Kipnis, D. M. Plasma insulin responses to glucose and tolbutamide of normal weight and obese diabetic and nondiabetic subjects. Diabetes 1966; 15: 867-874.

[39]. Pepino MY, Tiemann CD, Patterson BW, Wice BM, Klein S. Sucralose affects glycemic and hormonal responses to an oral glucose load. Diabetes care. 2013; 36(9):2530-2535.

[40]. Polonsky, K. S., Given, B. D., \& Van Cauter, E. Twenty-four-hour profiles and patterns of insulin secretion in normal and obese subjects. J Clin Invest 1988; 81: 442-448.

[41]. Qiu, C., Cotch, M.F., Sigurdsson, S., Garcia, M., Klein, R., Jonasson, F. Retinal and cerebral microvascular signs and diabetes the age, gene/environment susceptibility-reykjavik study. Diabetes 2008; 57: 1645-1650.

[42]. Reaven, G.M. Role of insulin resistance in human disease. Diabetes 1988; 37: 1595-1607.

[43]. Robertson, R. P., Harmon, J., Tran, P. O., Tanaka, Y., \& Takahashi, H. Glucose toxicity in beta-cells: type 2 diabetes, good radicals gone bad, and the glutathione connection. Diabetes 2003; 52: 581-587.

[44]. Resnikoff, S., Pascolini, D., Etya'ale, D., Kocur, I., Pararajasekaram, R., Pokharel, G.P., Mariotti, S.P. Global data on visual impairment in the year 2002. Bulletin of the World Health Organization 2004; 82: 844851.Robertson, R. P., Harmon, J., Tran, P. O., \& Poitout, V. Beta-cell glucose toxicity, lipotoxicity, and chronic oxidative stress in type 2 diabetes. Diabetes 2004; 53 (Suppl 1): 119-124.

[45]. Resnick, H.E., Howard, B.V. Diabetes and cardiovascular disease. Annual Review of Medicine 2002; 53: 245267.

[46]. Romaguera D, et al. Consumption of sweet beverages and type 2 diabetes incidence in European adults: results from EPIC-InterAct. Diabetologia. 2013; 56:1520-1530.

[47]. Rui, L., Yuan, M., Frantz, D., Shoelson, S., \& White, M. F. SOCS-1 and SOCS-3 block insulin signaling by ubiquitin-mediated degradation of IRS1 and IRS2. J Biol Chem 2002; 277: 42394-42398.

[48]. Swithers, S.E., Sample, C.H., and Davidson, T.L. Adverse effects of highintensity sweeteners on energy intake and weight control in male and obesity-prone female rats. Behav. Neurosci 2013; 127: 262-274.

[49]. Suez, J., Korem, T., Zeevi, D., Zilberman-Schapira, G., Thaiss, C.A., Maza, O., et al. Artificial sweeteners induce glucose intolerance by altering the gut microbiota. Nature 2014; 514: 181-186.

[50]. Saydah, S., Bullard, K.M., Cheng, Y., Ali, M.K., Gregg, E.W., Geiss, L., and Imperatore, G. Trends in cardiovascular disease risk factors by obesity level in adults in the United States, NHANES 1999-2010. Obesity, 2014; 22: 1888- 1895.

[51]. Stumvoll, M., Goldstein, B. J., \& van Haeften, T. W. Type 2 diabetes: principles of pathogenesis and therapy. Lancet 2005; 365: 1333-1346.

[52]. Shulman, G. I. Cellular mechanisms of insulin resistance. J Clin Invest 2000; 106: 171-176.

[53]. Stumvoll, M., Goldstein, B. J., \& van Haeften, T. W. Type 2 diabetes: principles of pathogenesis and therapy. Lancet 2005; 365: 1333-1346.

[54]. Suez J, Korem T, Zeevi D, Zilberman-Schapira G, Thaiss CA, Maza O, et al. Artificial sweeteners induce glucose intolerance by altering the gut microbiota. Nature. 2014; 514(7521):181-186.

[55]. Shanik, M. H., Xu, Y., Skrha, J., Dankner, R., Zick, Y., \& Roth, J. Insulin resistance and hyperinsulinemia: is hyperinsulinemia the cart or the horse? Diabetes Care 2008; 31: 262-268.

[56]. Tesfaye, S. Recent advances in the management of diabetic symmetrical polyneuropathy. Journal of Diabetes Investigation 2010; 2: 33-42.

[57]. Valko, M., Leibfritz, D., Moncol, J., Cronin, M.T., Mazur, M., Telser, J. Free radicals and antioxidants in normal physiological functions and human disease. The International Journal of Biochemistry \& Cell Biology 2007; 39: 44-84.

[58]. Wellen, K. E., \& Hotamisligil, G. S. Inflammation, stress, and diabetes. J Clin Invest 2005; 115: 1111-1119. 
DOI: $10.21522 / \mathrm{TIJBMS.2016.02.02.Art008}$

ISSN: $2519-500 \mathrm{X}$

[59]. Wolf, I., Sadetzki, S., Catane, R., Karasik, A., Kaufman, B. Diabetes mellitus and breast cancer. The Lancet Oncology 2005; 6: 103-111.

[60]. Yuan, S.Y., Breslin, J.W., Perrin, R., Gaudreault, N., Guo, M., Kargozaran, H. Microvascular permeability in diabetes and insulin resistance. Microcirculation 2007; 14: 363-373.

[61]. Yang Q. Gain weight by "going diet?" Artificial sweeteners and the neurobiology of sugar cravings: Neuroscience 2010. Yale J Biol Med. 2010; 83:101-108. 